\title{
التنسيق في تعليم اللغة العربية
}

\author{
مُحَّمَ زين الحمدي \\ جامعة دار العلوم بانيو أنيار باميكاسان لعلوم اللغة العربية
}

Hamdyhernandez14@gmail.com

\section{ملخص البحث}

المدرس هو قائد عملية التعليم والتعلم الذي يؤثر تأثيرا هاما في محاولة إلى صياغ

سلوك الدارسين. على إثر ذلك أن المدرس لا يعلّم ويدرس فقط وإنما هو يربي الدارسين ويشرفهم في جميع عمليتهم. ولإجراء وظيفته ومسئوليته على مدرس اللغة العربية أن يملك الكفاءة اللغوية الممتازة ويتبحر أيضا في العلوم المتعددة لكي يستطيع أن يؤثر الدارسين جانب المعري كان أم الوجداني والسلوكي.

فعلى المدرسة تعيين الأهداف المدروسة لتسهيل جميع الأفراد قياس للحصول إليها.

لذا تطوير التخطيط والتنظيم سواء كان التدريس أو المنهج أمر واجب له. وأيضا أن ينفع دوره لأجل زيادة الكفاءة المهنية للمعلمين الأخرين. فمن المعلوم للتنسيق الدور الرئيسي وهو تطوير عملية تكامل أفراد المدرس، وترقية قدرته وأداءه، وتطوير المنهج، وإجراء البحث لتصحيح عملية التدريس.

الكلمات المفتاحية: التنسيق، تعليم، اللغة العربية 


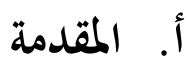

إن الإدارة قد ظهرت مع بداية استقرار الإنسان على الأرض، كمارصدت

مظاهر للعلمية الإدارية من الحضارات القديمة في مختلف العصور. إن تعدد الرغبات والأهداف والطموحات التي يسمى الإنسان إلى تحقيقها في هذا العمر المحدود، تتطلب منه أن يمارس الإدارة وبالأسلوب المناسب الذي يساعده على تحقيق ما له

$$
\text { في هذه الحياة. }
$$

ومن وظائفها العديدة تقوم بها شأها في ذلك شأن الإدارة العامة حيث بجد

إن أهم الوظائف هي: التخطيط، التنظيم، التنسيق، التوجيه، المتابعة، اتخاذ

$$
\text { القرارات، الاتصال، التقويم. }
$$

التنسيق هو من وظيفة الأدارة الذي يقوم به المديرون والهادف إلى توجيه

العاملين وتوحيد جهودهم نخو إنجاز عمل معين في وقت محدد وبأسلوب معين.

ويقصد به تحقيق الانسجام بين مختلف أوجه النشاط في المدرسة. ويتم هذا بعد

تحديد أهداف النشاط وتوزيع الأعمال بكل دقة. ويهدف التنسيق إلى عدم

التضارب في الاختصاصات المحددة للعاملين في المدرسة.

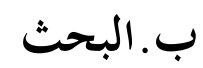

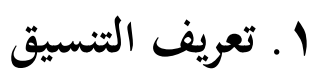

فيها تعاريف كثيرة للتنسيق التي اقترحها الخبراء في نظر كل منهم.

التنسيق يمكن أن يحدد تطبيقه في مجال التعليم، والجيش، والرياضة، والأعمال

$$
\text { التجارية والصناعة وغيرها من المجالات. }
$$

حدد أوروي تيد Ordway Tead أنه

"Leadership is the activity influencing people to cooperate some good which they come to find desirable" 
والتنسيق هو النشاط على تأثير الآخرين للعمل معا لتحقيق بعض الأهداف المنشودة' . وتعرّف سلامت سانتوسو عن التنسيق بأنه محاولة للتأثير

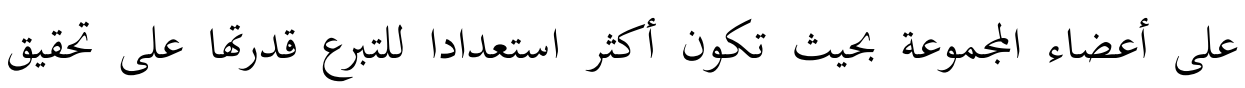
أهداف المجموعة التي تم الاتفاق '.

هناك تعريفات مختلفة ويبدو أن يكون دليلا على عدم مطابقة معنى على مفهوم التنسيق. وهكذا، فإن تعريف بجموعة متنمطة من التنسيق التي يمكن أن تستخدم إلا كما عقد مختلف هدف التنسيق. حتى رفض Laidlow

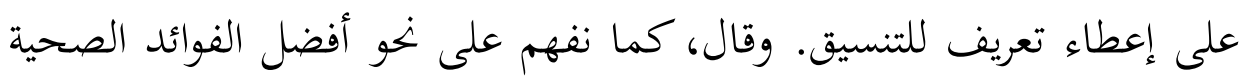
إذا كنت في حالة صحية، في حين يقيم في حالة صحية جيدة يشعر أنه لا يزال هناك النقص. فبعض الآراء الأخرى من الخبراء حول التنسيق هي كما يلي: أ) التنسيق هو سلوك شخص ما، عندما يدير أنشطة المجموعة نخو تحقيق الأهداف (Hemphill \& Coons) ب) التنسيق هو علاقة العمل بين أعضاء المجموعة حيث تمكن القائد الوضع من

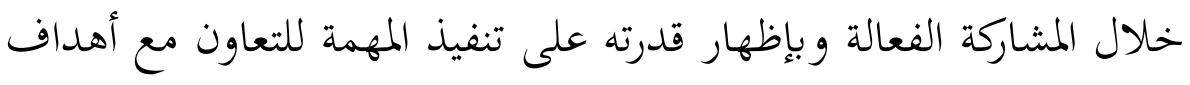
العمل (Stogdill) ج) التنسيق هو وسيلة للتفاعل مع الآخرين هي عملية اجتماعية التي تتضمن سلوك القائد المعين (Jenings)

د) التنسيق هو عملية توجيه أنشطة جماعة منظمة نحو تحقيق الأهداف (Rauch r \& Behling

هـ) التنسيق هو التأثير على أعضاء المجموعة دون إكراه لتوجيه وتنسيق أنشطتها من أجل تحقيق الأهداف . مانسيق

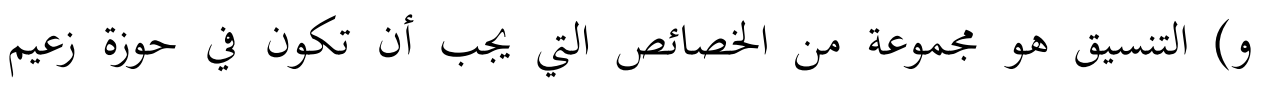

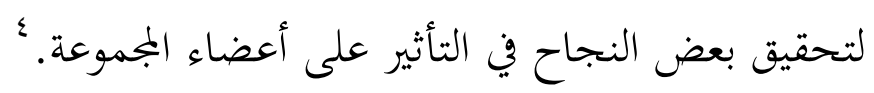

${ }^{1}$ Wursanto, Dasar-Dasar Ilmu Organisasi (Yogyakarta: Andi, 2003), hal. 196

${ }^{2}$ Slamet Santosa, Dinamika Kelompok (Jakarta: Bumi Aksara, 2004), hal. 44

${ }^{3}$ Asep Suryono, Diktat Kepemimpinan Pendidikan, 2010 (pdf) 
ز) التنسيق هو العمل الإداري الذى يقوم به المديرون والهادف إلى توجيه

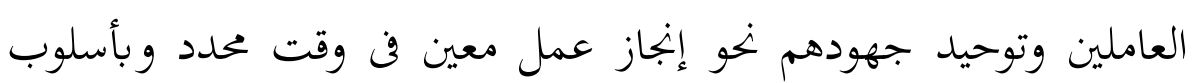
معين. ويقصد به تحقي الانسجام بين مختلف اوجه النشاط في المدرسة. ويتم

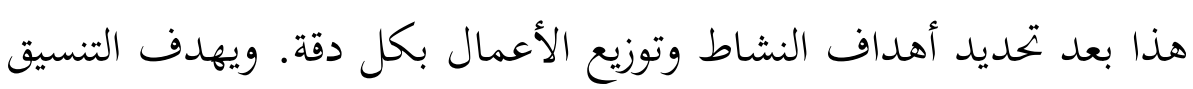

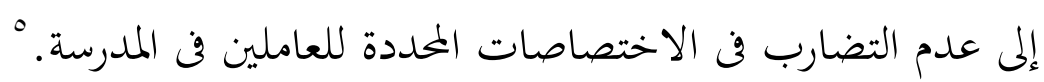

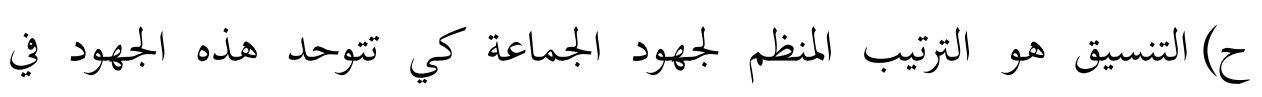

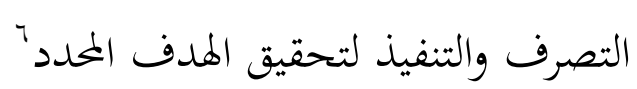

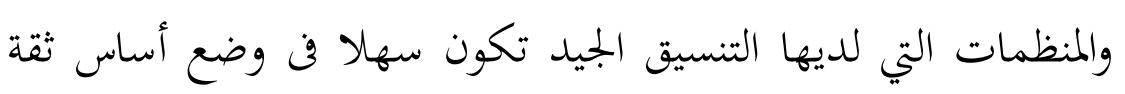

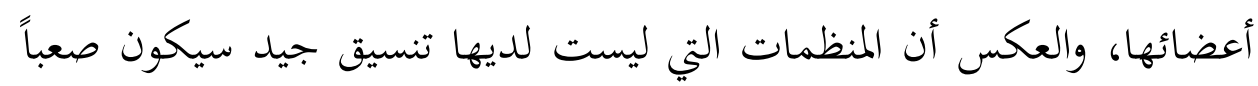

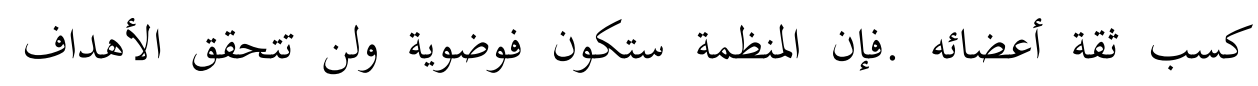
التنظيمية. فه تشابه هذا التعريف هو مجرد تستعد لنظام تصنيف التنسيق المبينة. فالتصنيف

$$
\begin{aligned}
& \text { هي: } \\
& \text { 1. . التركيز على عملية بجموعة } \\
& \text { r. الشخصية والنفوذ } \\
& \text { r. تحسين القيادة } \\
& \text { ع. المحاولة لزيادة نفوذ } \\
& \text { ه. موالفعل أو السلوك كرياده نعود } \\
& \text { 7. أشكال الإقناع }
\end{aligned}
$$

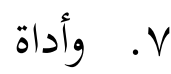

$$
\begin{aligned}
& \text { ^. مأثر التفاعل واهل }
\end{aligned}
$$

\footnotetext{
${ }^{4}$ Mukhtar dan Iskandar, Orientasi Baru Supervisi Pendidikan, (Jakarta, GP Press, 2009), hal. 76

• عباس بلة تُمَّم أحمد، مبادئ الإدارة الممدسية (وظائفها-مجالاتها-مهاراتها-تطبيقاتها)، (رياض، مكتبة الرشد، $\sum V \cdot V_{0} \cdot(r \cdot)$.

${ }^{6}$ http://almerja.net/reading
} 


$$
\text { 9. . . تماييز الأدوار }
$$

استنادا على التعريفات، فإن التنسيق لها الآثار العديدة :أولا، التنسيق تعني

إشراك الناس أو الأطراف الأخرى وهي موظف أو المرؤوسين. وينبغي لديهم استعداد

لقبول التوجيه. ومع ذلك، إن عدم الموظفين، فالتنسيق لن يكون موجودًا. ثانيا،

القائد الفعال هو شخص مع سلطته (له أو لها السلطة) يمكن أن يلهم اتباعه

$$
\text { لتحقيق الأداء المرضي. }
$$$$
\text { لذلك يمكن أن نستخلص من عدة تعريفات: }
$$

أ) أن التنسيق لديها بعض الجوانب في المشترك، وهي الأنشطة، والقدرة على

$$
\begin{aligned}
& \text { التأثير، وسلوك الآخرين، وإرادة الشعب والغرض منها. } \\
& \text { ب) يعد التنسيق مسؤولية ووظيفة كل مدير } \\
& \text { ج) ويستهدف التنسيق منع التشابك والتداخل داخل المنظمة } \\
& \text { د) يعد التنسيق وسيلة وغاية في آن واحد }
\end{aligned}
$$

ه) يطبق التنسيق على الأفراد، وعلى الجماعات، وعلى وحدات التنظيم

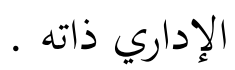

و ) التأكيد على وحدة الجهود والتصرفات هي جوهر وظيفة التنسيق

$$
\text { ز) يجب عدم الخلط بين مفهومي: التنسيق والتعاون }
$$

$$
\text { ح) التنسيق ليس حالة ساكنة، ولكنه عملية مستمرة ودائمة }
$$

ط) هناك ارتباط جذري وأساسي بين التنسيق كوظيفة، وبين بناء التنظيم نفسه

${ }^{7}$ Veithal Rivai dan Sylviana Murni, Education Management -Analisis Teori dan Praktik-, (Jakarta, Grafindo, 2009), hal. 285

8 Abdul Rohman, Pengertian Kepemimpinan Dalam Pendidikan (Telaah Pendekatan Fenomenologis Kritisis Kepemimpinan), (pdf) 
ي) يعتمد التنسيق على السلطة ، وأيضاً على كفاءة الأفراد، وعلى درجة الفهم والتعاون بين الأفراد.

ك) يجب إحداث وإيجاد التنسيق في المجالات الجديدة التي تظهر باستمرار في مختلف أنشطة التنظيم تتمثل أهم عناصر التنسيق في الآتى ?

$$
\begin{aligned}
& \text { أ) توجيه الجهود وتوحيدها } \\
& \text { ب)تحديد الوقت }
\end{aligned}
$$

ج) تحديد كمية ونمطية العمل المطلوب أدائه من كل قسم أو عنصر بشرى د) تحديد الشكل الذى يجب أن يسير على هجه العمل وينطلق الحاجة إلى التنسيق من الآتى '?

أ) لاختلاف الأفراد في فهمهم للقرارات الإدارية، أو السياسات واللوائح ونظم العمل ب)وكذلك اختلاف الأفراد في تقديرهم للأهداف المطلوبة

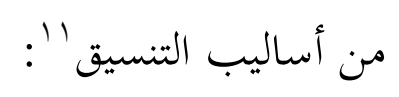

أ) التنسيق من خلال شرح الأهداف، تحديد الأعمال، وكيفية الأداء والوقت التقان ب) من خلال الوسائل غير الرسمية (مثل القرارات، الخطابات، النشرات الدورية، اللوائح)

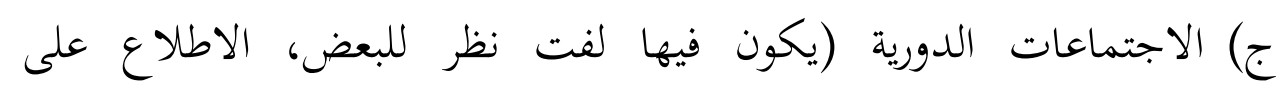
الانجازات المطلوبة، حل بعض المشكاتلات)

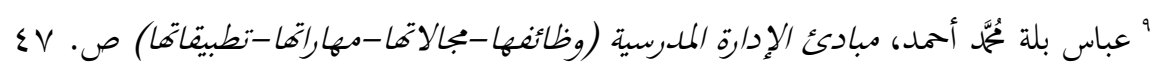

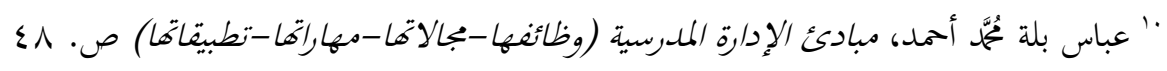

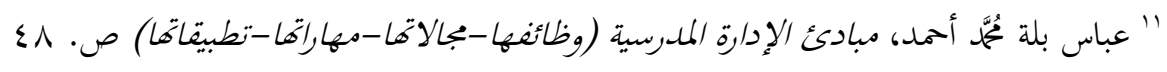




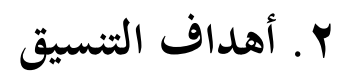

يهلدف التنسيق إلى أن يمسك كل خيوط التنظيمات الإدارية، وليعمل

منها بوصلة بابتحاه تحقيق الأهداف المرسومة بأعلى درجة من الكفاية وبأقل تكلفة ممكنة، هذا هو المدف الأساس لكن ثمة أهداف أخرى مثل

أ) منع التعارض في الاختصاصات: مثال على ذلك التعارض الذي يقع كثيرا في العالم الثالث خصوصا في العمل بين مصلحة المجاري من جهة ومصلحة

$$
\text { الطرق من جهة أخرى - من }
$$

ب) منع الازدواج في الأنشطة الإدارية: فقد يحدث أن تتعدد المنظمات الإدارية التي تقوم على تحقيق الأهداف واحدة أو متشاهة في مثل هذه الحالات يجب عمل التنسيق على تنظيم وتوحيد جهود هذه المنظمات حتى

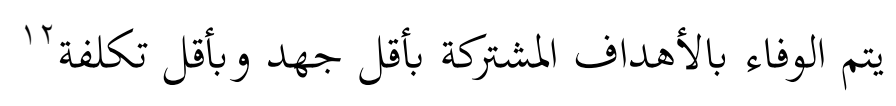
ج) منع المنافسة: فقد تتنافس المنظمات الإدارية في الحصول على المصدر

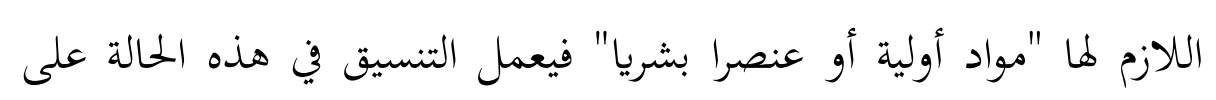

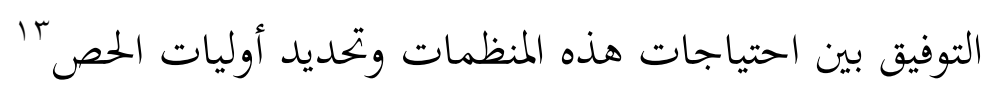

\section{ب. نظريات التنسيق}

التنسيق يتعلق كثيرا بإجراء العملية وعلاقة المجتمع على الأخرين. ؛ُ يرى الخبراء أن التنسيق هي أهم وظائف الإدارة الذي يكون مركزا رئيسيا في إجراء عمليتها. وهذا ما يراه أيضا أكثر المجتمع أن المنسق أو القائد هو الإله. وكيف

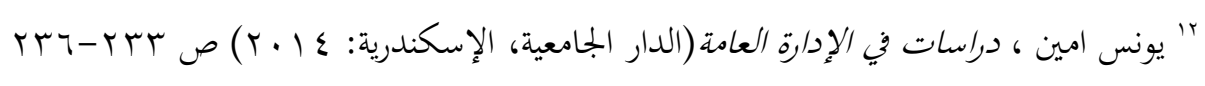

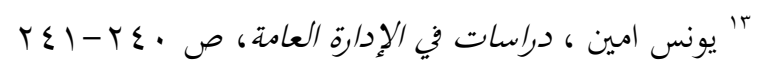

${ }^{14}$ Shoimatul Ula, Manajemen Pendidikan Efektif (Jogjakarta: BERLIAN, 2013), hlm. 22
} 
يستطيع الشخص أن يكون منسقا أم قائد؟ وهناك نظريات كثيرة التي تستطيع أن تجب تلك المشكلة.

\section{أ) نظرية Great Man}

يرى هذه النظرية أن التنسيق هو الملكة. وقال بني ونانوس أن هذه

النظرية تذهب بأن المنسق لايخلق وإنما هو يولد. ذهبت هذه النظرية يكون

التنسيق من وجه الوراثي أم من فرصة التي جاءت بوجود ملكة سببا لإيجاد

$$
\text { المنسق }
$$

\section{Big Bang نظبة نظية}

وأصبح تطورت تطورا تدريجيا بعد، بني ونانوس قالا أن نظرية Great

Big Bang مردود بوجود نظرية جديدة وهي نظرية الانفجار العظيم Man التي ترى أن المواقف العظيمة تؤدي إلى إيجاد المنسق. وهذه النظرية تكامل بين المواقف والأعضاء سببا لوجوده.

يقصد بالمواقف هي الأحوال المحدوثة التي تسبب صدور المنسق مثل

الثورة والفوضة و الإصلاحة وما إلى ذلك. ويقصد بالأعضاء هم الذين يؤيد

الشخص ليكون قائدا لمم ويطيعون ما أمرهم في كل حين ومكان.

ج) نظرية السِّمات

حيث تفسر هذه النظرية بأها بجموعة من الصفات التي يتصف بها

رجل الإدارة المدرسية، ويعتقد السماتيون أن القائد يتسم من المولد بسمات

${ }^{15}$ Abdul Aziz Wahab, Anatomi Organisasi dan Kepemimpinan pendidikan, (Bandung: ALFABETA, 2008), hlm. 84 
معينة وصفات خارقة تمكنه من احتلال موقع القيادة. والإدارة هي السلطة

$$
\text { المستمدة من شخصية الإداري. }
$$

يرى بني أن على القائدين أربع سمات منها:

Management of Attention إدارة الاهتمامي

Management of Meaning إدارة المعنوي

Management of Trust بـ إدارة الصدقي

ع. ع. إدارة الذاتي Management of Self

في عام بو9 1 قام تشارلزبيود ببحث عن الصفات القيادية وحصل

على عشرين قائمة تحتوى كل واحدة منها على مجموعة من الصفات أبرزها

(الأمانة، الإخلاص، الطموح، الشهامة، المبادرة، الذكاء، النزاهة).

ويرى برنارد إن القيادة ذات جانبين الجانب الأول مهما يتعلق

بالفنون القيادية ويستلزم تمتع الشخص بالمقدرة الفعلية والمهارة والقدرة على

تفهم الظواهر، الجانب الثاني فيتعلق بتوفر خصائص العزيمة، التصميم،

الشجاعة.

ويرى أخرون إن أهم صفات القيادة هي الذكاء، بعد النظر، حصافة

الرأي، الوزن، المظهر، الصوت، القدرة على التعبير، المركز الاجتماعي،

القدرة على تحميل المسؤولية' .

والأخير، في نظرية السمات خصائص القائد التي قد حددها

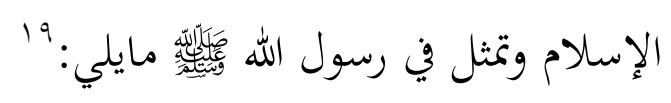

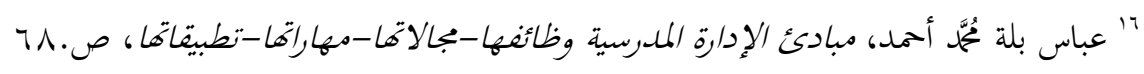

${ }^{17}$ Abdul Aziz Wahab, Anatomi Organisasi dan Kepemimpinan pendidikan, hlm. 85

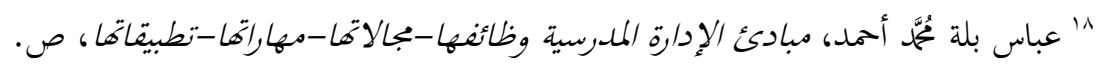

${ }^{19}$ Abdul Aziz Wahab, Anatomi Organisasi dan Kepemimpinan pendidikan, hlm. 86 


$$
\begin{aligned}
& \text { 1. الصديق } \\
& \text { r. الأمانة } \\
& \text { r. التبليغ } \\
& \text { ـ. الفطانة } \\
& \text { ه. المعصوم }
\end{aligned}
$$

وكما اختلف الكتاب في إبراز الصفات العامة للقائد، فكان اختلاف

طبيعة هذه الصفات هل هي صفات فطرية أم مكتسبة، ويرى البعض أن الصفات يمكن أن تكتب بالتجربة وبالتعليم.

وتكتسب نظرية السمات قوهّا من بعض الدراسات الميدانية حيث إن

بعضها اثبت إن هناك علاقة بين الكفاءة القيادية وبين الصفات الشخصية.

وقد وجد غيزلى إن هنالك علاقة بين القيادة الفعالة وبين بعض

الصفات الشخصية مثل الذكاء، القدرة الإشرافية، المبادرة، الثقة بالنفس بَ.

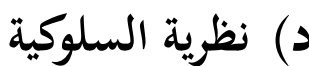

هذه النظرية تَتم اهتماما كثيرا إلى تحليل سلوك القائد، بيان خوائص عمليته لتحقيق أهداف المجموعة. ومن خوائصه هي سلوك القائد، سلوك

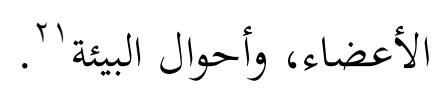

\section{هـ) نظرية الموقف}

تأخذ هذه النظرية بالموقف وطريقة الفرد في علاجه، والقائد في نظر القائلين بهذه النظرية هو أحسن من يعالج المواقف، وهذه النظرية تعطي

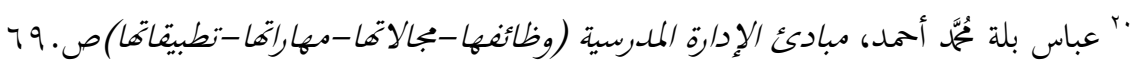
hlm. 289

\footnotetext{
${ }^{21}$ Veithal Rivai dan Sylviana Murni, Education Management-Analisis Teori dan Praktik
} 
للقيادة صفة وطبيعة معينة. وتتلخص مفاهم النظرية بأن المواقف والظروف المختلفة تتطلب أساليب إدارية مختلفة.

ويرى أنصار هذه النظرية إن ليس هنالك طريقة واحدة أفضل من

غيرها. فالطريقة المثلى تعتمد على الظروف والحالات المعينة، أمثلة:

( ) هتلر في ألمانيا

r) ايزهاور كقائد عسكري لقوات الحلفاء خلال الحرب العالمية

الثانية هي التي أدت إلى انتخابه رئيسا للولايات المتحدة سنة

. 1907-190r

r) وهذا يعني إن بروز القادة إنما يعتمد على المشكلات التي تواجه

المجموعة باختيار القائد. ومن يتولى القيادة يكون أقدر أفراد

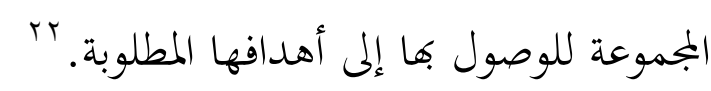

\section{و) نظرية التفاعلية}

فهي نظرية مشتركة بتمع بين السمات والموقف، فالقائد في نظر القائلين بهذه النظرية هو الشخص الذي يستطيع أن يحدث بين شخصية وما يمتلكه من السمات والموقف الذي يواجهه بحيث يحقق أهداف الأفراد والمنظمة.

وتنظر هذه النظرية للقيادة على إذا وظيفة فقط. يتولاها من هو أصلح لوقت معين وموقف معين يتنحي في موقف أخر. ومن هنا كانت دينامية القيادة وهي صفة الحركة المتنقلة المتغيرة. 
وإن الفرد يصبح قائد ليس من منطلق الشخصية فقط، وإنما أيضا

من الظروف المخيطة، ودرجة التفاعل بين الفرد والظروف.

ويرى فيدلر (مطور هذه النظرية) أن العناصر التي تتوثر في فعالية

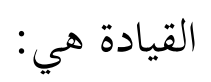

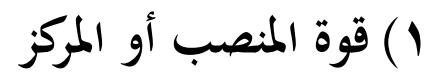

ويقصد بهذه القوة، السلطة الرسمية التي تعطيها الوظيفة أو المركز القيادي للقائد والتي يستطيع بموجبها ووجودها إصدار أوامره وتعليماته على الأخرين والالتزام بتنفيذها، وبدون وجود سلطة واضحة فان تبعية الأعضاء أو المرؤوسين تصبح مثار شك

$$
\text { وتفسير. }
$$

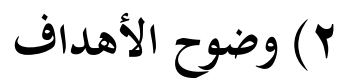

أي كلما كانت الأهداف واضحة والواجبات محدده، وكلما كان أمام القائد بدائل معينة لحل المشكلات، وإن ذلك يساعد على

$$
\begin{aligned}
& \text { تأكيد فعالية القيادة، والعكس صحيح. } \\
& \text { ץ) العلاقات بين القائد والأعضاء }
\end{aligned}
$$

العلاقة بين القائد وأعضاء مجموعته فلها تأثير كبير على مدى فعالية قيادته، وهي تتوقف على طبيعة شمور المجموعة نحو القائد. وهل هو شعور ودي أم غير ودي، تأييدي أم معارض،

$$
\text { متوتر أم متساهل. }
$$


يعتمد المنسق أو القائد في ممارسته لأسلوب التأثير على الأخرين وكسب

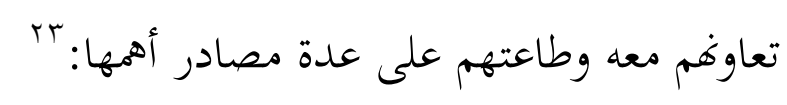

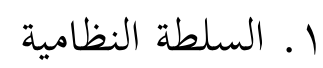

وهي السلطة الممنوحة للمدير بحكم العمل الإداري، وهي شرطة رسمية

شرعية عن طريقها يصدر أوامره، ويتخذ القرار الذي يحقق الإنجاز

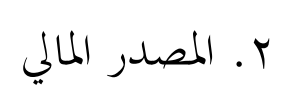

أي الوسائل المالية من مكافات نقدية وعينية كأسلوب للتأثير في

المرؤوسين بعد الامتثال للأوامر والتعليمات لتحقيق الأهداف

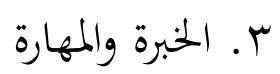

القائد الذي لديه خبرات وبتحارب في بجال الأعمال التي يمارسها يحظي باحترام مرؤوسيه، واقتناعهم بقدرته على التصدي لمشاكلهم.

$$
\text { ع. التأثير الشخصي }
$$

وهي بجموعة الميزات والسمات الشخصية، وهي مصدر مهم في التأثير على الأخرين مثل القدرة على الإقناع، المعاملة الحسنة، حب الأخرين وغير ذلك. هـ التأثير النابع من الاحترام

الاحترام شيء، والمودة والحب شيء أخر، وقد يبنى المرؤوسين احترامهم لرئيسهم من منطلقات عدة مثل المركز الاجتماعي، المهارة والحبرة، النزاهة الشخصية.

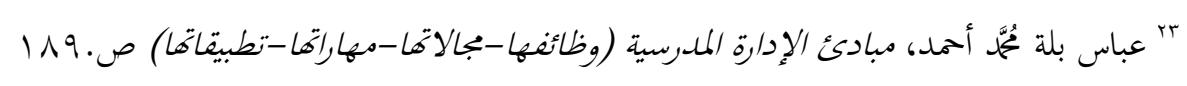




\section{هـ العلاقة بين التنسيق والعمليات الإدارية \\ ومن العلاقة بين التنسيق والعمليات الإدارية هي: گ⿸厂}

أ) العلاقة بين التخطيط والتنسيق: من المهم جداً تحقيق التكامل بين الخطط، وهذا لا يتأتى إلا بضمان التنسيق بينها تصميماً وانجازاً فلو أردنا مثلاً إضافة منتج جديد لباقة منتجاتنا. فإن ذلك يتطلب أنشطة في التصميم، والانتاج، والعمليات والموارد وهذا يحتاج بغير شك إلى التنسيق. ب)العلاقة بين التنظيم والتنسيق :إذا كان التنظيم يعني تحديد العلاقات بين الوحدات الإدارية في المنظمة ، وكذا تحديد السلطات والمسؤوليات لكل فرد في هذه الوحدات ، فإن التنسيق يلعب دورا رئيساً في توزيع الأنشطة المختلفة على الأقسام المعنية وما يرافق ذلك من سلطات ومسؤوليات .ويؤثر التنظيم على حجم ونوعية التنسيق المطلوب وهذا يرتبط بما سبق أن أطلقنا

$$
\text { عليه (نطاق الإشراف) }
$$

ج) العلاقة بين التوجيه والتنسيق : يعد التنسيق أحد أدوات التوجيه من خلال مشاركة الأفراد في تحديد الأهداف، ورسم الخطط وكلما كان حجم المنظمة صغيرا كلما كان تحقيق التنسيق بين جهود الأفراد أمراً سهل المنال. وكلما كانت العلاقات الإنسانية عميقة، وكلما هيأت الإدارة للعاملين ظروف

$$
\text { عمل جيدة، كلما خفف ذلك من كثير من مشكلات العمل. }
$$

د) العلاقة بين الرقابة والتنسيق : إن الهدف من الرقابة هو ضمان تحقيق الأهداف المطلوبة، وتصحيح الانحرافات حال حدوثها، وبالمثل فإن الهدف من التنسيق هو ضمان تحقيق هذه الأهداف من خلال توحيد جهود

\section{${ }^{24}$ http://almerja.net/reading.php?idm=46621}


الأفراد. مع ملاحظة مهمة وهي الانحراف عن النتائج قد يكون بسبب الخلل في التنسيق، ولذا تصحيح هذه الانحرافات من خلال الوظيفة الرقابية يترتب عليها أيضا تصحيح الخلل في التنسيق

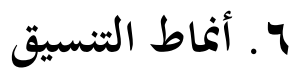

وفقا للخبراء، أنماط أساسية من التنسيق هي السلطوية والديمقراطية، ودعه ليعمل. من ثلاثة أنماط أساسية من التنسيق ينشأ نمط آخر من التنسيق • . ومن بين عدة أنماط من التنسيق التربوية، هي كما يلي:

أ) نمط استبدادية، في هذا النمط من التنسيق الاستبدادية، يريد الزعيم هو المزيد من السلطة، وبالتالي جو المدرسة هو دائما متوترة. لا يعطي الزعيم حرية للمرؤوسين للمشاركة في اتخاذ قرار لقضية معينة، والقرار الوحيد الذي تهري بذها به زعيم. في هذه الحالة، أن الزعيم يملي دائما ما ينبغي القيام به من

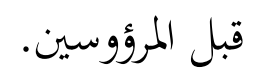

ب)نمط عدم التدخل، طبيعة هذا النمط من التنسيق كما لو لم تنشأ، لأن القادة إعطاء الحرية الكاملة لأعضائه في القيام بواجباتم، والمرؤوس في هذه الحالة لديه فرصة كبيرة لاتخاذ قرار.

ج) نمط الديمقراطية، ويمكن القول أن هذا النمط من التنسيق الديمقراطية هو نمط التنسيق التي من المتوقع ضمن المدرسة .وبالنظر إلى أن، الشركة الرائدة دائما بما في ذلك في هذا النمط من تنسيق المرؤوسين كامل في عمليات صنع القرار ـويثمن القادة الآراء والإبداع لأعضاء هيئة التدريس والموظفين

\footnotetext{
${ }^{25}$ Mujamil Qomar, Manajemen Pendidikan Islam, (Jakarta, Erlangga, 2007), hal. 275
} 
في البيئة المدرسية، بحيث المرؤوسين سيشارك مسؤولة عن تنفيذ البرنامج في

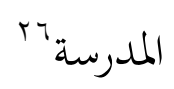

د) نمط الاستبدادي، وتعتبر نمط من زعيم أن الزعيم هو الحق .ومن بين

الخصائص المميزة للزعيم من هذا النمط هو :نفترض أن تملكها المنظمة من

القطاع الخاص، ويحدد الهدف شخصية مع الأهداف التنظيمية، ترى أن

المرؤوس هو نمط وحدها، على استعداد لقبول النقد، والاقتراحات، وآراء

الآخرين، في تحريك المرؤوسين غالبا ما تستخدم النهج التي تحتوي على

$$
\text { الإكراه. }
$$

هـ نمط العسكرية، الزعيم من نمط العسكرة لديها خصائص على النحو التالي :

في عمل المرؤوس يصل الأمر يستخدم الوجهة كأداة رئيسية، في تحريك

المرؤوس أحب استخدام رتبة، وسعيدة لالشكليات المفرطة، وطالب

الانضباط والطاعة المطلقة من المرؤوسين، وليس على استعداد لتقبل النقد

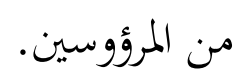

و) نمط أبوي، الأبوي نمط التنسيق له خصائص معينة، وهي الأبوي .تنسيق

مثل هذا يستخدام تأثير الأبوي في تحريك الطبيعة تابعة للأهداف. قد

$$
\text { يكون النهج عاطفي جدا. }
$$

ز) نمط الكاريزمية، نمط من التنسيق الكاريزمية هو نمط من الزعيم الذي يتمتع

بجاذبية هائلة، وبالتالي لديه أتباع ضخمة .ونظرا لعدم وجود القائد

الكاريزمي، كثيرا ما يقال إن مثل هذا القائد هبت مع قوى خارقة للطبيعة .

\footnotetext{
${ }^{26}$ Mukhtar dan Iskandar, Orientasi Baru Supervisi Pendidikan hal. 85
} 
الكاريزمية أسلوب التنسيق هو السلطة الطبيعية تمتلك زعيما، ليس بسبب

$$
\text { أي شرعية سياسية لتشكيل تتم بشكل منهجي. }
$$

من الناحية العملية، إنشاء منتجات تعليمية تصبح المهنيين، تحتاج شخصية زعيم موثوق بها. شكل هذا الزعيم وفقا Atmodiwirio قادة التعليم قادرة على جلب مجموعة متنمطة من المفاهيم التربوية التي يمكن أن تستوعب تتكيف مع التغيرات في الاجتماعية والاقتصادية، والتكنولوجيا، لذلك هم

$$
\text { يستعدّون لمواجهة بسبب التغيرات في عصر العولمة. }
$$

هناك حاجة إلى تنسيق لإحداث تغييرات بناءة في البرامج التعليمية وفقا

لقيم وأهداف صناع القرار. تقود التعليم هو التعلم. ربّما أن يكون مبنى المدرسة بسيط، وكذلك المرافق المكتبية، والنقل، ومقاعد، والجداول، وهكذا دواليك . ومع ذلك، يجب أن يكون التعليم أعظم من الجوانب الأخرى. جودة التعليم ستكون على المحك من خلال عملية التعلم. ووفي الوقت نفسه، فإن نمط عملية التعلم تتضمن تكييف كل من الكفاءة المهنية للمعلمين، والتوعية من الطلاب للدراسة بجد والإعلام والتعليم والتعلم، وبيئة التعلم. V . التنسيق في ججال التعليم

هناك علاقة بين الإدارة والتنسيق Sondang P. Siagian يؤكد أن الأساس من التنسيق هي إدارة ومظهر الأكثر وضوحا من الإدارة هو التنسيق جr في إدارة التربية الإسلامية، يتأثر تنفيذ التنسيق بعوامل مختلفة. وفقال H. Jodeph Reitz التي استشهد بها Nanang Fattah ، وهذه العوامل هي:

${ }^{27}$ Saefullah, Manajemen Pendidikan Islam, hal. 168-170

${ }^{28}$ Mujamil Qomar, Manajemen Pendidikan Islam hal. 271

${ }^{29}$ Sondang P. Siagian dalam Mujamil Qomar, Manajemen Pendidkan Islam, (Jakarta, Erlangga, 2007), hal. 268 
أ) شخصية قادة وخبرها الماضية وتوقعاةما. وهذا يشمل القيم والخلفيات، وسوف الخبرات تؤثر على اختيار أسلوب التنسيق .التربية الإسلامية في الإدارة، شخصية الرئيسي لزعيم هو قدوته التي ينبغي أن يحتذى من قبل

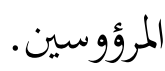

ب)توقعات وسلوك الرؤساء تتعلق بالغرض من التنسيق، وهي انشأ بعضها البعض في البر والصبر.

ج) الخصائص والتوقعات والسلوكيات تؤثر تابعة لأسلوب التنسيق تطبيقها . أسلوب الأمثل هو اسلوب تنسيق النبي تُجَّمْ الذي دائما الحفاظ على الانضباط والمهنية، الرأفة، والعمبة، وتطوير التعاون. د) الحاجة للقيام بهذه المهمة، وسيكون لكل المرؤوسين تؤثر أيضا على نمط زعيم، و يجب المرؤوسين طاعة رئيسه هـ) المناخ والسياسات التنظيمية تؤثر على توقعات المرؤوسين وسلوكهم بناء نظام وطني للتعليم الجيد هو العاطفة والرؤية للمؤسسات التعليمية التي تنفيذه . المشكلة هي كيفية توليد الرغبة والرغبة في بناء نظام التعليم الوطني الذي بالتأكيد من أجل تحسين نمطية التعليم في حد ذاته. Petters dan Austin في كتابه $A$ Passion for Excellence 


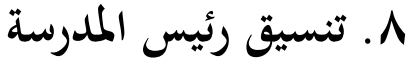

بيتزز (Peters) وأوستن (Austin) يعطي أهمية خاصة في التنسيق التربوية في

فصل بعنوان التميز في التنسيق المدرسية(Excellence in School Leadership). وهم

يعتقدون أن مدير المدرسة كقائد تربوي يتطلب وجهات النظر التالية.

أ) الرؤية والرموز. يجب على مدير المدرسة تواصل القيم المؤسسة للموظفين

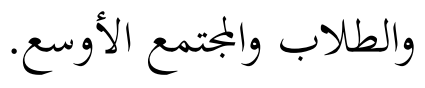

ب) management by walking about أوارارة عن طريق المشي) هي

$$
\text { إدارة لتنفيذ أسلوب التنسيق اللازمة للمؤسسة. }
$$

ج) للطلاب. هذا المصطلح مرادف "على مقربة من العملاء". هذا يؤكد أن

$$
\text { المؤسسة لديها تركيز واضح على عملائها الرئيسي. }
$$

د) الاستقلال الذاتي، والتجريب، وتوقع الفشل .يجب أن القيادات التربوية بذل الابتكار بين موظفيها وعلى استعداد لتوقع الفشل التي تقترن هذه

$$
\text { الابتكارات. }
$$

هـ إيجاد شعور بالأمن القرابة .يجب على القادة خلق شعور الأسرة بين الطلاب

$$
\text { وأولياء الأمور والمعلمين وموظفي المؤسسة. }
$$

و) الإخلاص والصبر، والعاطفة، وكثافة، والحماس هي الصفات الجودة

$$
\text { الشخصية الضرورية اللازمة للمؤسسات التعليمية. }
$$

مدير المدرسة كقائد هو القوة الدافعة الرئيسية والعملية الرئيسية على نطاق المدرسة. ولذلك، فإن مدير المدرسة له دور كبير جدا فيما يتعلق بالتعليم .من منظور السياسة الوطنية للتعليم (وزارة التعليم الوطني، ج · . †) وهناك سبعة أدورا 
رئيس المدرسة رئيسيا وهي على النحو التالي : المعلم أو المربي، والمديرين، وإداريين،

والمشرف، وزعيم، و المبتدعة من مناخ العمل، و رجال الأعمال. ابr

الكفائات التى لا بد أن يملكها رئيس المدرسة:

\begin{tabular}{|c|c|c|}
\hline الكفاءة & أبعاد الكفاءة & رقم \\
\hline 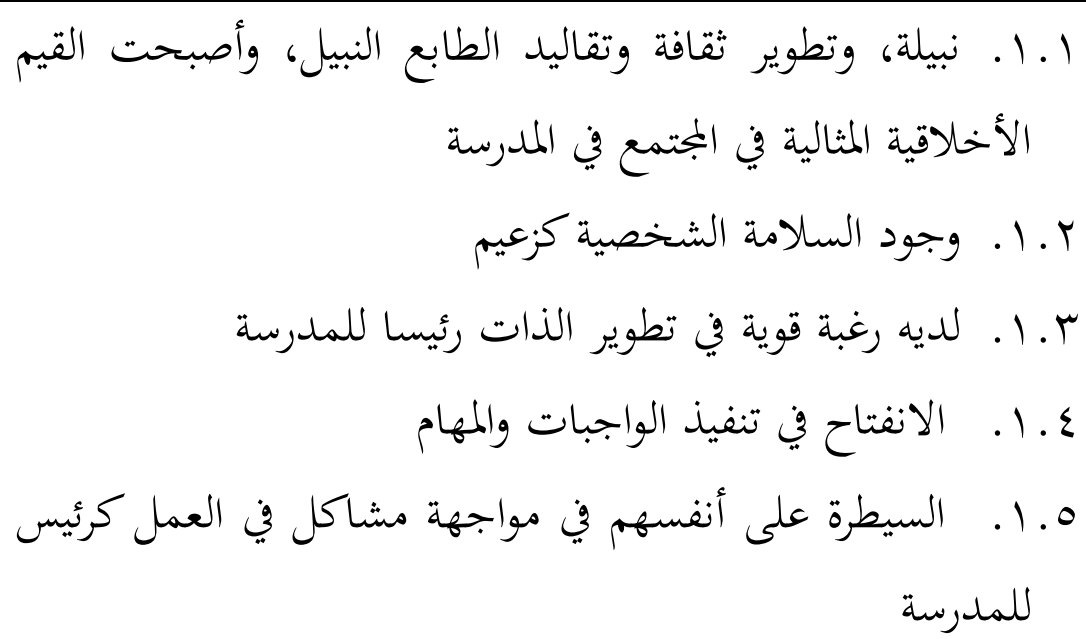 & شخصية & .1 \\
\hline 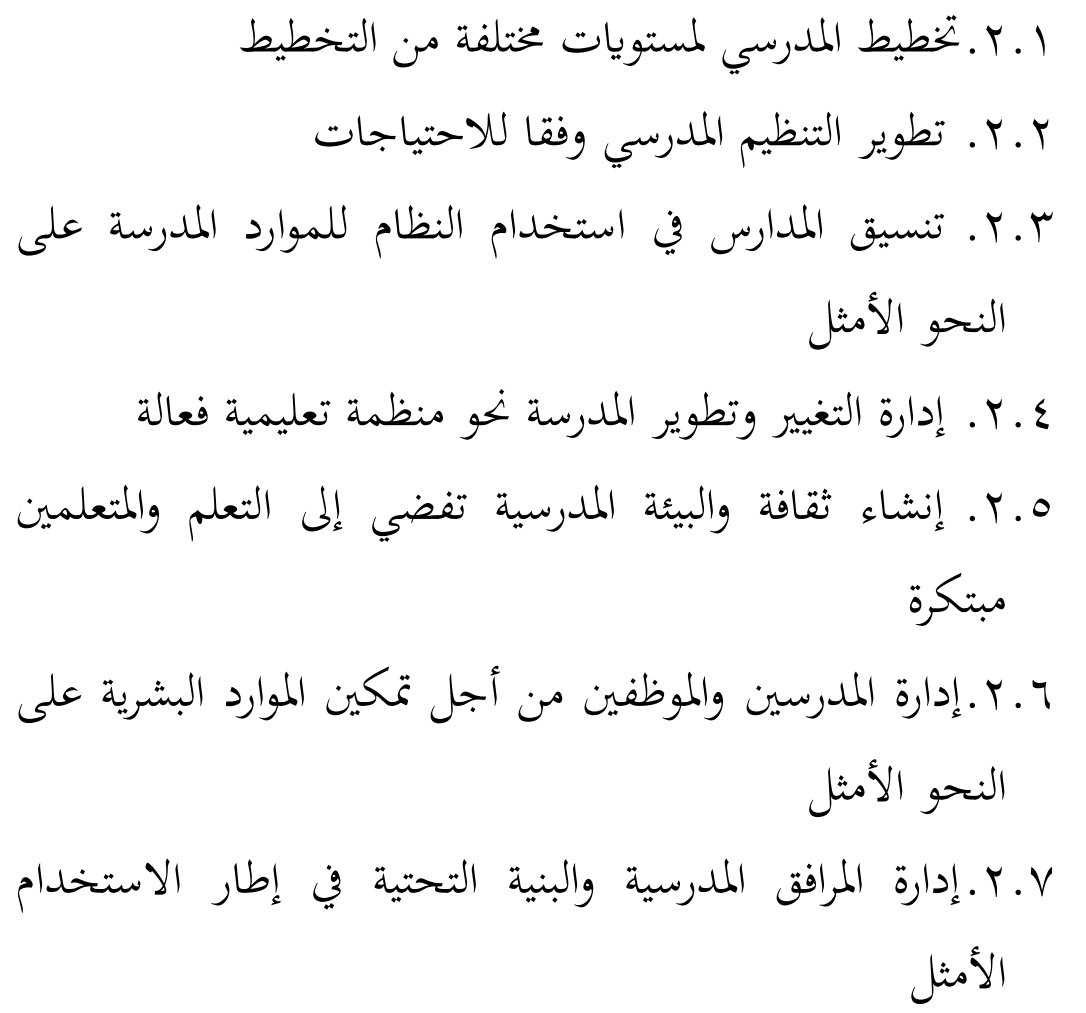 & إدارية & .1 \\
\hline
\end{tabular}

${ }^{31}$ Mukhtar dan Iskandar, Orientasi Baru Supervisi Pendidikan hal.80

${ }^{32}$ Muhaimin, Suti'ah, Sugeng Listyo, Manajemen Pendidikan (Jakarta, Kencana, 2009), hal. 42-44 
ي.r. إدارة العلاقات المدرسة والمجتمع من أجل إيجاد أفكار جديدة وموارد التعلم، وتمويل المدارس 9. . . إدارة المتعلمين في توظيف المتعلمين الجدد، ووضع وتطوير

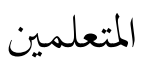
• . . . إدارة تطوير المناهج الدراسية والأنشطة وفقا لاتجاه وأهداف التربية الوطنية التعلم 1ا.Y. إدارة الشؤون المالية المدرسة وفقا للمبادئ مساءلة الإدارة،

$$
\text { وشفافية، وكفاءة. }
$$

Y Y. Y. إدارة إدارة المدرسة في دعم تحقيق أهداف المدرسة

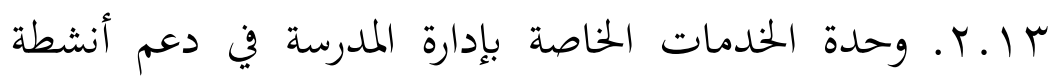

$$
\text { التعلم والأنشطة من المتعلمين في المدارس وإدة }
$$

ـ ا.Y. إدارة نظام المعلومات المدرسية في دعم البرامج واتخاذ

$$
\text { القرارات }
$$

1. 1. الاستفادة من التقدم في بجال تكنولوجيا المعلومات

$$
\text { لتحسين التدريس والإدارة في المدرسة }
$$

I ا. Y. الرصد والتقييم، والإبلاغ عن تنفيذ برنامج أنشطة المدرسة

$$
\text { ا. م. إنشاء الإجراءات المناسبة، والتخطيط لمزيد من أعمال }
$$

r.ب. العمل الجاد لتحقيق نجاح المدرسة كمنظمة تعليمية فعالة r.r. يملك دافعا قويا للنجاح في تنفيذ الواجبات والمهام كزعيم

$$
\text { المدرسة }
$$

ع. r. تتخلى أبدا ودائما تبحث عن أفضل الحلول في التعامل مع

$$
\text { المشاكل في المدرسة المتحس }
$$

ه.r.لديهم روح المبادرة في إدارة الأنشطة أو خدمات المدرسة 


\begin{tabular}{|c|c|c|}
\hline الإنتاج والمتعلمين ومصادر التعلم & & \\
\hline 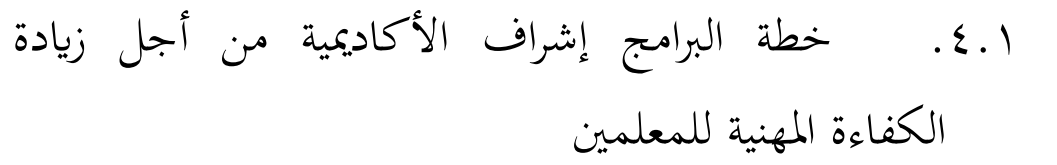 & إشراف &.$\varepsilon$ \\
\hline 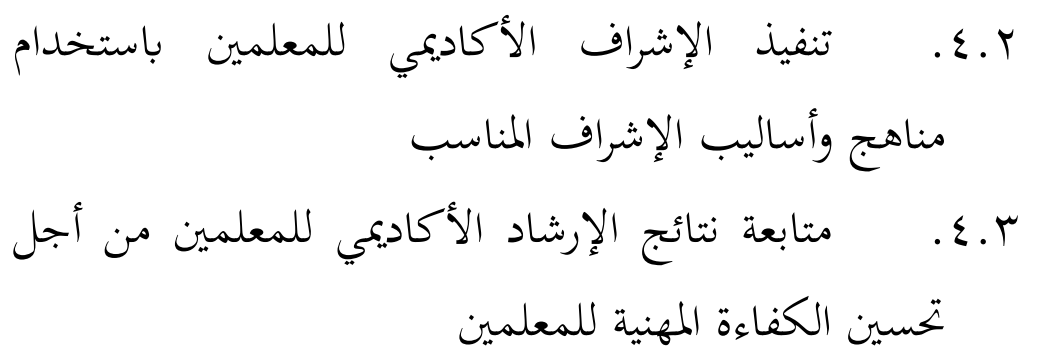 & & \\
\hline 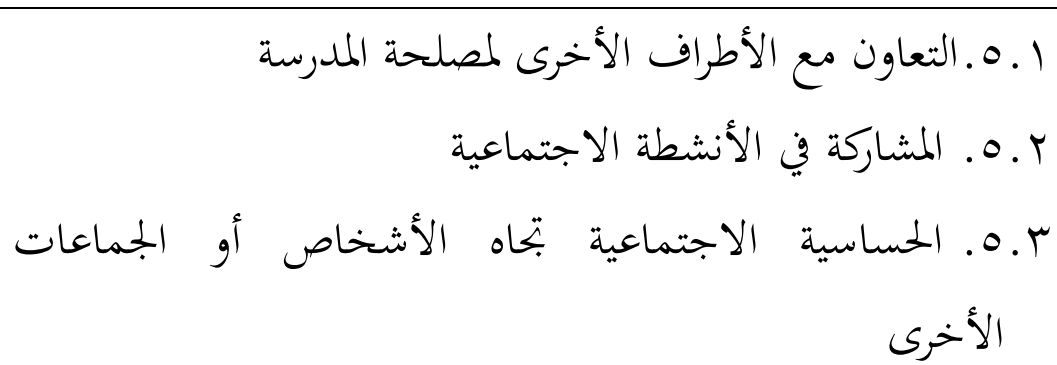 & اجتماعية & .0 \\
\hline
\end{tabular}

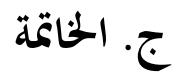

من المعلومات أو البحوث التي يجصل عليها الباحث، سوف نعرف كيف التنسيق في التدريس خاصة في تدريس اللغة العربية. فمن المعلوم للتنسيق الدور الرئيسي ألا وهو تطوير عملية تكامل أفراد المدرس، ترقية قدرته وأداءه، تطوير المنهج، وإجراء البحث لتصحيح عملية التدريس. فالمدرس هو قائد عملية التعليم والتعلم الذي يؤثر تأثيرا عميقا في محاولة إلى صياغ سلوك الدارسين. على إثر ذلك أن المدرس لا يعلّم ويدرس فقط وإنما هو يربي الدارسين ويشرفهم في جميع عمليتهم. ولإجراء وظيفته ومسئوليته على مدرس اللغة العربية أن يملك الكفاءة اللغوية الممتازة ويتبحر أيضا في العلوم المتعددة لكي يستطيع أن يؤثر الدارسين جانب المعرفي كان أم الوجداني والسلوكي. 


$$
\begin{aligned}
& \text { فعلى المدرسة تعيين الأهداف المدروسة لتسهيل جميع الأفراد قياس للحصول } \\
& \text { إليها. لذا تطوير التخطيط والتنظيم سواء كان التدريس أو المنهج أمر واجب له. } \\
& \text { وأيضا أن ينفع دوره لأجل زيادة الكفاءة المهنية للمعلمين الأخرين. } \\
& \text { المصادر والمراجع } \\
& \text { عباس بلة تُحَّة أحمد. مبادئ الإدارة الملدسية وظائغها-مجالاتها-مهاراتها-تطبيقاتها. رياض: }
\end{aligned}
$$

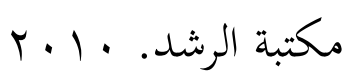

$$
\begin{aligned}
& \text { يونس امين ، درامات في الإدارة العامة(الدار الجامعية، الإسكندرية: ع ا • ب) }
\end{aligned}
$$

Muhaimin. Suti'ah. Sugeng Listyo. Manajemen Pendidikan. Jakarta: Kencana. 2009

Mukhtar. Iskandar. Orientasi Baru Supervisi Pendidikan. Jakarta: GP Press. 2009

Qomar, Mujamil. Manajemen Pendidikan Islam. Jakarta: Erlangga. 2007

Rivai, Veithal. Murni, Sylviana. Education Management-Analisis Teori dan Praktik-. (Jakarta: Grafindo. 2009

Rohman, Abdul. Pengertian Kepemimpinan Dalam Pendidikan Telaah Pendekatan Fenomenologis Kritisis Kepemimpinan

Saefullah. Manajemen Pendidikan Islam. Bandung: Pustaka Setia. 2012

Santosa, Slamet. Dinamika Kelompok. Jakarta: Bumi Aksara. 2004

Sondang. Manajemen Pendidikan Islam. Jakarta: Erlangga. 2007

Suryono, Asep. Diktat Kepemimpinan Pendidikan. 2010

Ula, Shoimatul. Manajemen Pendidikan Efektif. Jogjakarta: BERLIAN. 2013

Wahab, Abdul Aziz. Anatomi Organisasi dan Kepemimpinan pendidikan. Bandung:

ALFABETA. 2008

Wursanto. Dasar-Dasar Ilmu Organisasi. Yogyakarta: Andi. 2003

http://almerja.net/reading 